\title{
The Effect of High Pressure-Low Temperature Treatment on Physicochemical Properties in Milk
}

\author{
H. Y. Kim, ${ }^{*}$ S. H. Kim, ${ }^{*}$ M. J. Choi, $†$ S. G. Min, $†$ and H. S. Kwak*1 \\ *Department of Food Science and Technology, Sejong University, Seoul 143-747, Korea \\ †Department of Food Science and Biotechnology of Animal Resources, Konkuk University, Seoul 143-701, Korea
}

\begin{abstract}
This study was carried out to investigate the effect of high pressure-low temperature (HPLT) treatment on physicochemical properties and nutrients in milk. The milk was treated at $200 \mathrm{MPa}$ and $-4^{\circ} \mathrm{C}$ for 10,20 , and $30 \mathrm{~min}$. Protease and lipase activities of HPLT-treated milk were highly inactivated compared with that of raw milk. Among time treatments, the 30-min treatment showed the lowest activities compared with others. Absorbance of thiobarbituric acid increased with time in HLPT-treated milks; however, no difference was observed between the raw milk and milk treated for $10 \mathrm{~min}$. The concentrations of short-chain fatty acids except $\mathrm{C}_{4}$ in HPLT-treated milks increased with time. The total free amino acids in HPLT-treated milks were greater than that of the raw milk for the 30-min treatment. L-Ascorbic acid, niacin, and riboflavin in HPLTtreated milks were significantly lower compared with concentrations in raw milk. For color, the L-value of HPLT-treated milks was significantly lower than that of the raw milk; however, there was no difference in the a-value for $10 \mathrm{~min}$ and in the b-value at $20 \mathrm{~min}$ between the raw milk and the HPLT-treated milks.
\end{abstract}

Key words: high pressure-low temperature treatment, physicochemical property, milk nutrient

\section{INTRODUCTION}

During the past 20 yr there has been increasing interest in the application of high pressure (HP); that is, in the range of about 100 to $1,000 \mathrm{MPa}$, to various food systems as an alternative method for preservation as well as for modifying certain physical properties of food constituents (Knorr, 1993; Buchheim et al., 1996). The application of HP technology has become the subject of renewed interest in the food industry as it offers the opportunity to produce foods of high sensory and nutritional quality with extended shelf-life without the

Received November 20, 2007.

Accepted June 17, 2008.

${ }^{1}$ Corresponding author: kwakhs@sejong.ac.kr use of additives (Hong et al., 2006). The first studies on milk processing using HP date to the end of the 19th century (Hite, 1899). However, it was not until 1990 that equipment advances and the consumer demand for minimally processed high-quality foods have lead to a considerable research interest in HP technology (López-Fandiño, 2006). In fact, HP is the only process technology alternative to heat treatment that has reached the consumer in a variety of products, including fruit jams, jellies, sauces, juices, avocado pulp, and cooled ham, although there are not, as yet, commercial HP-treated dairy products. Most of the applications take advantage of the fact that HP exerts antimicrobial effects without impairing nutritional quality (Sancho et al., 1999). However, in addition to satisfying consumer demands for fresh products free from additives, HP may offer a clear competitive advantage in creating unique effects in food that may overcome the constraint of the large capital investment required.

Milk is a dairy product that is heat-treated using a range of conditions to provide acceptable safety and shelf-life. The resistance of microorganisms to pressure in food is variable and depends on HP processing conditions (e.g., pressure, time, temperature, cycles), food constituents, and the properties and the physiological state of the microorganism (Kolakowski et al., 2000).

In addition to the inhibition and destruction of microorganisms, HP influences the physicochemical and technological properties of milk. When milk is subjected to HP, the casein micelles disintegrate into smaller particles (Trujillo et al., 2002) with a decrease in milk turbidity and lightness of color, and an increase of viscosity of the milk (Huppertz et al., 2002). Furthermore, the pressure-induced dissociation of the colloidal calcium phosphate and denaturation of serum proteins in milk may change or improve its technological properties. In addition to microbial destruction, the effects of HP on protein structure and mineral equilibrium suggest different applications on dairy products, including the microbiological stabilization of milk and dairy products (cream, yogurt, and cheese), the processing of milk for cheese and yogurt production, and the preparation of dairy products with novel textures. 


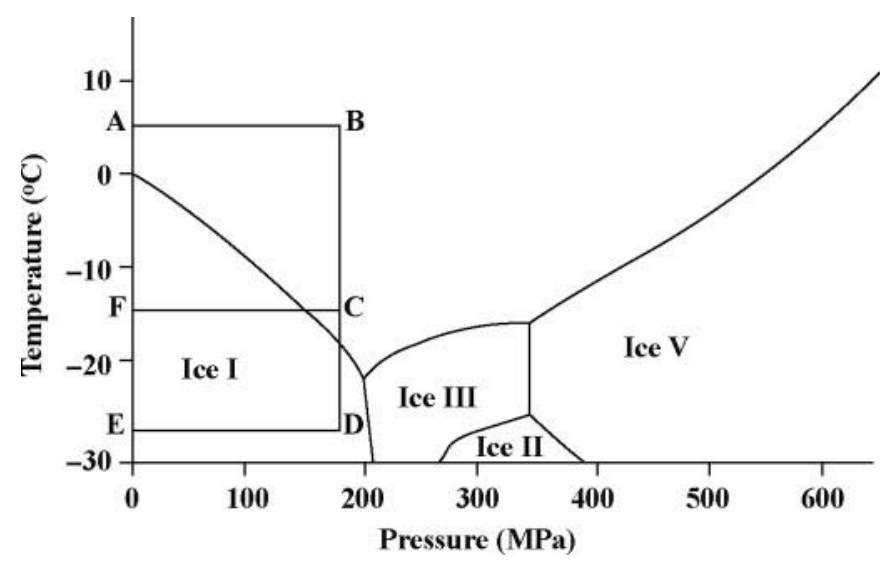

Figure 1. Schematic paths on the phase diagram of water and ice in high-pressure domain.

Studies carried out by Gervilla et al. (2001) on the FFA content (lipolysis of milk fat) in ewe's milk showed that HP treatments between 100 and $500 \mathrm{MPa}$ at 4, 25, and $50^{\circ} \mathrm{C}$ did not increase FFA content, and some treatments at $50^{\circ} \mathrm{C}$ showed lower FFA content than fresh raw milk. Even though pressure up to $500 \mathrm{MPa}$ produces some modifications in the size and distribution of milk fat globules of ewe's milk (Gervilla et al., 2001), no damage to the milk globule membranes occurred, as evidenced by the lack of increase in lipolysis. These modifications on distribution of milk fat globules could be due to phenomena of aggregation and disaggregation or disintegration. This provides some advantages of HP-treated milk.

In the high-pressure domain, the phase transition temperature of water decreases to a minimum of $-22^{\circ} \mathrm{C}$ at $210 \mathrm{MPa}$ (Wagner et al., 1994), followed by the phase transition line (Figure 1). Urrutia Benet et al. (2004) suggested definitions and terminology regarding these phase transition phenomena and process descriptions, which were named pressure-assisted freezing (shown as $\mathrm{A} \rightarrow \mathrm{B} \rightarrow \mathrm{D} \rightarrow \mathrm{E}$ in Figure 1), pressure-assisted thawing (shown as $\mathrm{E} \rightarrow \mathrm{D} \rightarrow \mathrm{B} \rightarrow \mathrm{A}$ ), and pressure shift freezing ( $\mathrm{A} \rightarrow \mathrm{B} \rightarrow \mathrm{C} \rightarrow \mathrm{F} \rightarrow \mathrm{E}$ ). In pressure-assisted freezing and thawing, phase transition occurs at a decreased phase transition temperature and latent heat of water. In pressure shift freezing, a sample is cooled below $0^{\circ} \mathrm{C}$ and above its phase transition temperature under pressure, and is then subjected to instant pressure release before decreasing to the phase transition temperature.

Recently, Luscher et al. (2005) found that the HP treatment between 150 and $300 \mathrm{MPa}$ at subzero temperatures could result in a pasteurization effect in foods. Luscher et al. (2005) called this processing highpressure cold pasteurization. However, the effect of HP treatment in milk at subzero temperatures has not been studied yet from the viewpoints of microbial inactivation and physicochemical properties. We can postulate the technical possibility that HP may be available as a processing technology to achieve the same potential quality of milk as that treated by conventional heat processing. Therefore, the objective of the present study was to investigate, as a first step, the effects of HP on the physicochemical properties of milk.

\section{MATERIALS AND METHODS}

\section{Pressure Treatment}

Pressurization was performed using high-pressure equipment manufactured by ourselves (Hong et al., 2006). The equipment comprised pressure vessel with a working volume of $1 \mathrm{~L}$, an air compressor (S-40, Seowon Compressor Co., Seoul, Korea), a pressure intensifier (HSF-300, Haskel International Inc., Burbank, CA), a temperature controller (FP80, Julabo Labortechinik $\mathrm{GmbH}$, Seelbach, Germany), and a mobile recorder (MV104, Yokogawa Co., Osaka, Japan). A polyethylene bag $(4.5 \mathrm{~mm}$ diameter $\times 100 \mathrm{~mm})$ was filled with raw milk and tightly sealed after inserting a thermocouple. The sample was stored at $4^{\circ} \mathrm{C}$ (refrigerator temperature) before pressurization. Ethylene glycol was used as the compression fluid, and pressurization was carried out at $200 \mathrm{MPa}$ and measured for 10,20 , and 30 min when the sample temperature reached $-4^{\circ} \mathrm{C}$. The pressure level was monitored by digital gauge (SSGA, Sensys Co., Bucheon, Gyeonggi-do, Korea). After treatment, the sample temperature increased to $4^{\circ} \mathrm{C}$ by heating before the pressure is released. All samples were stored at $4^{\circ} \mathrm{C}$ before analysis.

\section{Enzyme Activities and $\mathrm{pH}$}

To examine the effect of the HP treatment on enzyme activities, the activities of protease and lipase were measured (Chae, 2002). pH measurement was carried out using a pH meter (Model 440, Corning, SchipholRijk, the Netherlands) at an ambient temperature and was measured in triplicate.

\section{Thiobarbituric Acid Test}

Oxidation products were analyzed spectrophotometrically using the thiobarbituric acid (TBA) test (Hegenauer et al., 1979). The TBA reagent was prepared immediately before use by mixing equal volumes of freshly prepared $0.025 M$ TBA, which was neutralized with $\mathrm{NaOH}$, and $2 \mathrm{M} \mathrm{H}_{3} \mathrm{PO}_{4} / 2 M$ citric acid. Reactions of the TBA test were started by pipetting $5.0 \mathrm{~mL}$ of 


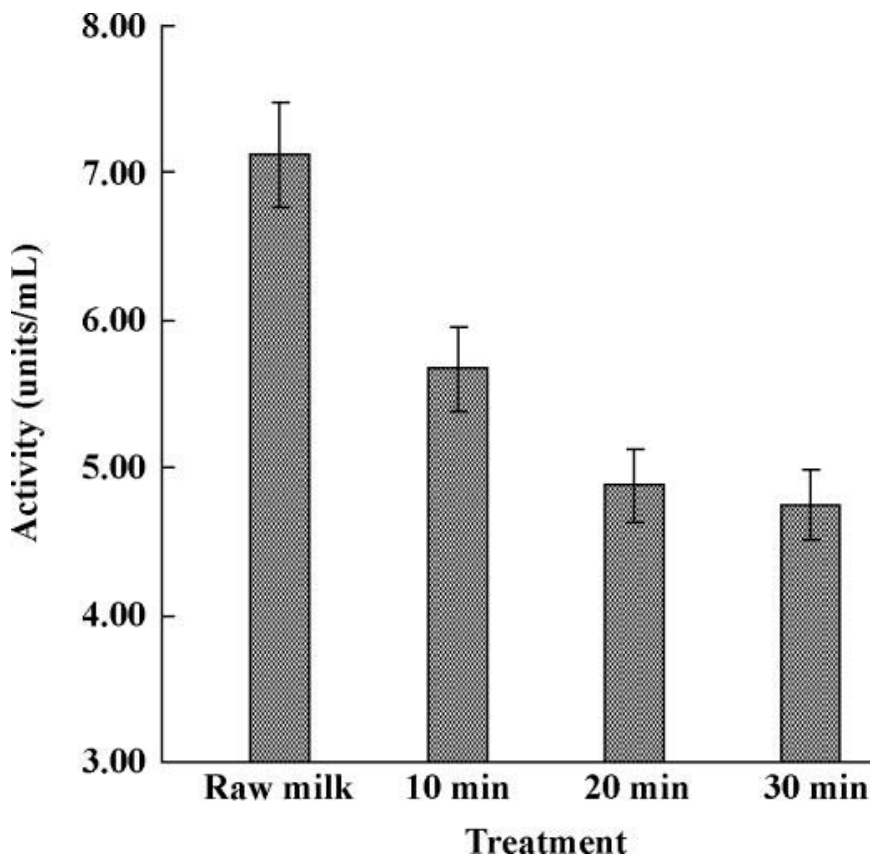

Figure 2. Changes in protease activity of high pressure-low temperature treated milk at $200 \mathrm{MPa}$ and $-4^{\circ} \mathrm{C}$.

milk sample into a glass centrifuge tube and mixing thoroughly with $2.5 \mathrm{~mL}$ of TBA reagent. The mixture was heated immediately in a boiling water bath for exactly $10 \mathrm{~min}$ and cooled on ice. Ten milliliters of cyclohexanone and $1 \mathrm{~mL}$ of $4 \mathrm{M}$ ammonium sulfate were added and centrifuged (HMR-220IV, Hanil Industrial Co., Seoul, Korea) at $2,490 \times g$ for $5 \mathrm{~min}$ at room temperature. The orange-red cyclohexanone supernatant was decanted, and its absorbance at $535 \mathrm{~nm}$ was measured spectrophotometrically in a 1-cm light path. All measurements were run in triplicate.

\section{Short-Chain FFA}

Milk samples (1 mL) were removed periodically, extracted with diethylether and hexane for $2 \mathrm{~h}$, and eluted through a $10-\mathrm{mm}$ (internal diameter) glass column containing neutral alumina as described by Ikins et al. (1988). A Hewlett-Packard (Palo Alto, CA) model 5880A GC equipped with a flame-ionization detector was used. The preparation of FFA was achieved using a $15 \mathrm{~m} \times 0.53 \mathrm{~mm}$ (internal diameter) Nukol fusedsilica capillary column (Supelco Inc., Bellefonte, PA). The GC was operated with helium carrier gas at 2 $\mathrm{mL} / \mathrm{min}$, hydrogen gas $37 \mathrm{~mL} / \mathrm{min}$, and air at $300 \mathrm{~mL} /$ min. The column oven was programmed as an initial holding for $1 \mathrm{~min}$ at $110^{\circ} \mathrm{C}$ and first level holding to $180^{\circ} \mathrm{C}$ at $5^{\circ} \mathrm{C} / \mathrm{min}$ for $10 \mathrm{~min}$ and holding for $20 \mathrm{~min}$. Temperatures for injector and detector were $250^{\circ} \mathrm{C}$. All quantitative analyses were done by relating each peak area of individual FFA to the peak area of tridecanoic acid as an internal standard. Each FFA was identified by the retention time of the standard.

\section{Free Amino Acids}

To determine free AA, $5 \mathrm{~g}$ of milk was mixed with 5 $\mathrm{mL}$ of distilled water. Then, $500 \mathrm{mg}$ of sulfosalicyclic acid was added to the mixture, which was stored at $4^{\circ} \mathrm{C}$ for $1 \mathrm{~h}$ and centrifuged at $1,300 \times \mathrm{g}$ for $15 \mathrm{~min}$. The supernatant was filtered through a $0.45-\mu \mathrm{m}$ filter paper and pretreated by the method described by Lindroth and Mopper (1979). Determination of free AA by using HPLC was done by the modified method of Hodgin et al. (1983). Flow rate was $2 \mathrm{~mL} / \mathrm{min}$ and 2 mobile phases were used: solvent A was $0.05 M$ sodium acetate $(\mathrm{pH}$ 6.3), and solvent B was methanol:tetrahydrofuran $(90: 10, \mathrm{vol} / \mathrm{vol})$. The linear gradient of solvent B was programmed at 5 levels as follows: starting at $20 \%$, then increasing to $40 \%$ for $6 \mathrm{~min}$, to $42 \%$ for $9 \mathrm{~min}$, to $50 \%$ for $3 \mathrm{~min}$, and finally to $70 \%$ for $12 \mathrm{~min}$. Free AA were analyzed on an ODS- $\mu$-Bondapak C column (3.9 $\mathrm{mm} \times 30 \mathrm{~mm}$ ), and an HPLC (Waters, Plymouth, MN) equipped with a refractive index detector was used. All quantitative analyses were performed by relating peak areas of individual free AA to those of external standard amino acids (Wako, Osaka, Japan). All samples were analyzed in triplicate.

\section{Water-Soluble Vitamins}

To determine water-soluble vitamins, $0.5 \mathrm{~mL}$ of milk was placed in a $50-\mathrm{mL}$ volumetric flask, mixed with mobile phase, and sonicated for $20 \mathrm{~min}$. The mixed solution was centrifuged at $452 \times \mathrm{g}$ for $20 \mathrm{~min}$, filtered, and injected into HPLC. Vitamins were analyzed on Shodex RSpak DE-413L column $(4.6 \times 250 \mathrm{~mm}$, Thomson Instrument Co. and Shodex Inc., Clear Brook, VA), and a HPLC (Waters) equipped with a RI detector was used. Flow rate was $0.5 \mathrm{~mL} / \mathrm{min}$ and 2 mobile phases were used: solvent A was $0.005 M$ sodium hexane sulfonate, and solvent B was a mixture of $0.4 \mathrm{~mL}$ of triethylamine in $15 \mathrm{~mL}$ of methanol:acetic acid (1:1, vol/vol). The linear gradient of solvent B was programmed at 5 levels as follows: initial starting at $20 \%$, then increasing to $40 \%$ for $6 \mathrm{~min}$, to $42 \%$ for $9 \mathrm{~min}$, to $50 \%$ for $3 \mathrm{~min}$, and finally to $70 \%$ for $12 \mathrm{~min}$. All quantitative analyses were performed by relating peak areas of individual vitamins to those of external standards (Wako). All samples were analyzed in triplicate.

\section{Color}

Color measurement was taken with a colorimeter (CR210, Minolta, Tokyo, Japan) after calibrating its 
Table 1. Changes in $\mathrm{pH}$ and thiobarbituric acid (TBA) values of high pressure-low temperature treated milk at $200 \mathrm{MPa}$ and $-4^{\circ} \mathrm{C}$

\begin{tabular}{lcc}
\hline Treatment & $\mathrm{pH}$ & TBA \\
\hline Raw milk & $6.69 \pm 0.02^{\mathrm{a}}$ & $0.044 \pm 0.003^{\mathrm{a}}$ \\
$10 \mathrm{~min}$ & $6.70 \pm 0.03^{\mathrm{a}}$ & $0.042 \pm 0.001^{\mathrm{a}}$ \\
$20 \mathrm{~min}$ & $6.69 \pm 0.01^{\mathrm{a}}$ & $0.048 \pm 0.002^{\mathrm{b}}$ \\
$30 \mathrm{~min}$ & $6.69 \pm 0.02^{\mathrm{a}}$ & $0.052 \pm 0.001^{\mathrm{b}}$ \\
\hline
\end{tabular}

${ }^{\mathrm{a}, \mathrm{b}}$ Means within a column with the same superscript are not significantly different $(P>0.05)$.

original value with standard plate $(\mathrm{X}=97.83, \mathrm{Y}=$ 81.58, $\mathrm{Z}=91.51)$. Measured L-, a-, and b-values were regarded as indicators of lightness, redness, and yellowness, respectively. The total color difference, $\Delta \mathrm{E}=$ $\left[(\Delta \mathrm{L})^{2}+(\Delta \mathrm{a})^{2}+(\Delta \mathrm{b})^{2}\right]^{1 / 2}$, between raw milk and treated sample was calculated numerically. Three measurements were taken from each sample.

\section{Viscosity}

The viscosity of samples $(30 \mathrm{~mL})$ was measured at $5^{\circ} \mathrm{C}$ using a viscometer (LV type, Brookfield Engineering Laboratories Inc., Stoughton, MA) with a single spindle at $100 \mathrm{rpm}$. All samples were measured in triplicate.

\section{Statistical Analysis}

One-way ANOVA (SAS Institute, 1985) was used. The significance of the results was analyzed by the LSD test. A difference of $P<0.05$ was considered significant.

\section{RESULTS AND DISCUSSION}

\section{Enzyme Activities}

The protease activity following high pressure-low temperature (HPLT) treatment is shown in Figure 2. The protease activity of HPLT-treated milks was significantly lower than that of the raw milk $(P<0.05)$. The protease activities were 7.12 and 5.67 unit/mL, respectively, in the raw milk and in the HPLT-treated

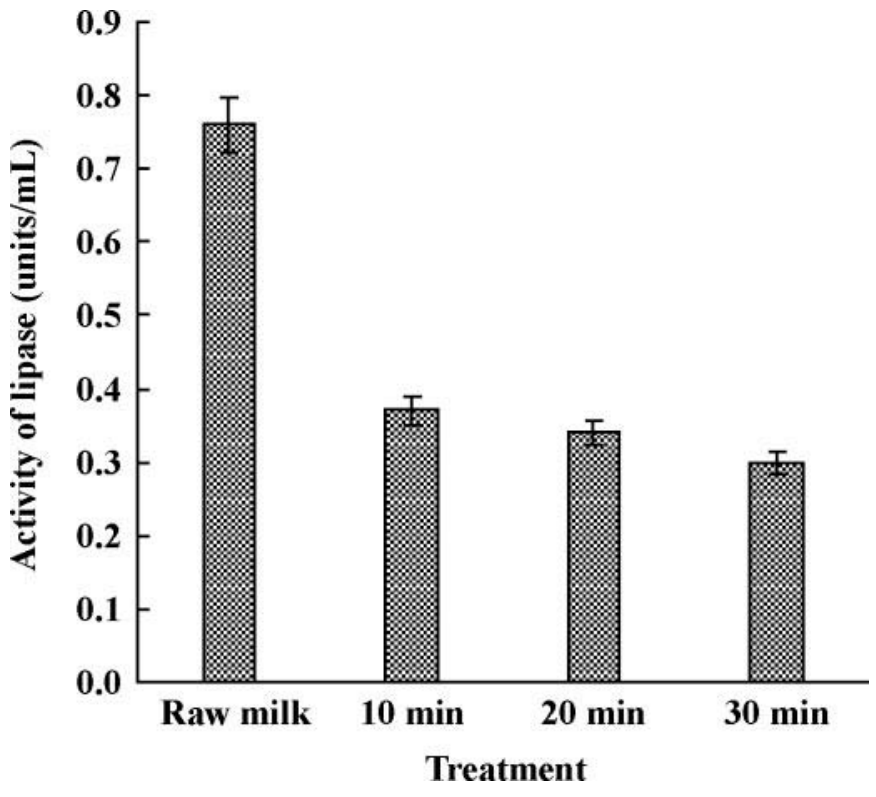

Figure 3. Changes in lipase activity of high pressure-low temperature treated milk at $200 \mathrm{MPa}$ and $-4^{\circ} \mathrm{C}$.

milk at $10 \mathrm{~min}$. Among the HPLT-treated milks, a significant difference was found at 10 min compared with the other times; however, no difference was found between the 20- and 30-min treatments. The present study indicated that about $34 \%$ of activity was reduced after the 20-min treatment.

There was a greater reduction in lipase activity with HPLT treatment compared with protease activity (Figure 3). Even the 10-min treatment showed a 51\% reduction of activity. Lipase activity was 0.76 unit/ $\mathrm{mL}$ in the raw milk and in the range of 0.30 to 0.37 unit/mL in HPLT-treated milks and those were significantly different $(P<0.05)$. At $200 \mathrm{MPa}$, the activities of protease and lipase decreased significantly $(P<0.05)$. A progressive reduction in the activity of enzymes was observed with increasing treatment time. The loss in activity with increasing time was dramatic in protease activity but not in lipase activity. The above results indicated that HPLT treatment for about 20 min might reduce the activities of protease and lipase in milk.

Table 2. Short-chain free fatty acid concentrations of high pressure-low temperature treated milk at $200 \mathrm{MPa}$ and $-4^{\circ} \mathrm{C}$

\begin{tabular}{lccccc}
\hline & \multicolumn{4}{c}{ Concentration of short-chain FFA (ppm) } \\
\cline { 2 - 6 } Treatment & $\mathrm{C}_{4}$ & $\mathrm{C}_{6}$ & $\mathrm{C}_{8}$ & $\mathrm{C}_{10}$ & Total \\
\hline Raw milk & $2.52 \pm 0.1^{\mathrm{a}}$ & $1.01 \pm 0.05^{\mathrm{a}}$ & $0.91 \pm 0.05^{\mathrm{a}}$ & $2.67 \pm 0.1^{\mathrm{a}}$ & $7.12 \pm 0.3^{\mathrm{a}}$ \\
10 min & $2.61 \pm 01^{\mathrm{a}}$ & $1.17 \pm 0.06^{\mathrm{a}}$ & $0.92 \pm 0.05^{\mathrm{a}}$ & $2.79 \pm 0.1^{\mathrm{a}}$ & $7.49 \pm 0.3^{\mathrm{a}}$ \\
20 min & $2.60 \pm 0.1^{\mathrm{a}}$ & $1.23 \pm 0.06^{\mathrm{a}}$ & $1.16 \pm 0.05^{\mathrm{ab}}$ & $2.96 \pm 0.1^{\mathrm{a}}$ & $7.95 \pm 0.3^{\mathrm{b}}$ \\
30 min & $2.75 \pm 0.1^{\mathrm{a}}$ & $1.65 \pm 0.07^{\mathrm{b}}$ & $1.28 \pm 0.06^{\mathrm{b}}$ & $3.20 \pm 0.1^{\mathrm{b}}$ & $8.88 \pm 0.3^{\mathrm{c}}$ \\
\hline
\end{tabular}

\footnotetext{
${ }^{\mathrm{a}-\mathrm{c}}$ Means within a column with the same superscript are not significantly different $(P>0.05)$.
} 


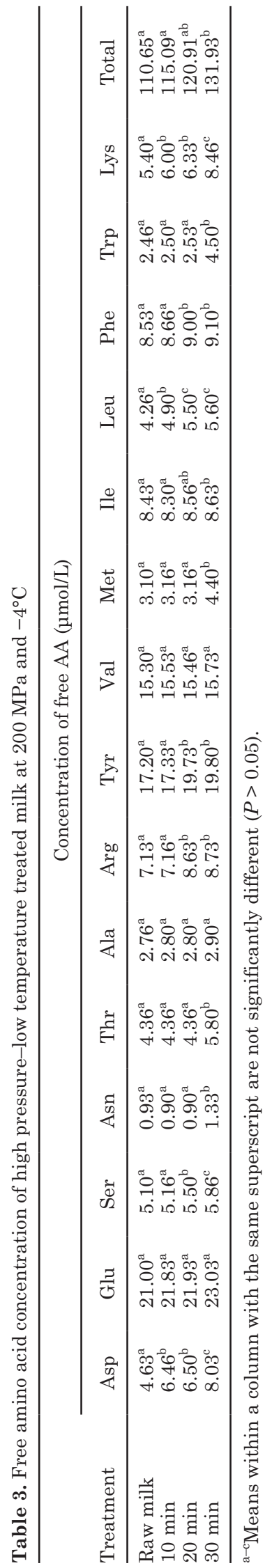

pH

The $\mathrm{pH}$ values of the raw and treated milks were in the standard range of fresh milk (Table 1), which is 6.6 to 6.8. This result indicated that HPLT treatment did not affect the $\mathrm{pH}$ level in the milk samples.

\section{TBA Test}

Absorbance of TBA slightly increased following the 20- and 30-min treatments; however, the 10-min treatment did not significantly $(P>0.05)$ affect TBA value. The TBA value in the raw milk was 0.044, compared with 0.052 in the 30 -min treated milk (Table 1). Even though it was significantly greater, the TBA value in the 30-min treatment was relatively low compared with values obtained following other milk processing methods such as pasteurization by heating or freezing treatment in milk. Therefore, these results indicated that the HPLT treatment may not induce any dramatic lipid oxidation in milk.

\section{Short-Chain FFA}

The production of short-chain FFA in HPLT treatment of milk is shown in Table 2. When the HPLT treatment was applied for less than $20 \mathrm{~min}$, individual concentrations of short-chain FFA were not significantly different from that of the raw milk. However, in the 30-min treatment, a slight but significant increase occurred in HPLT-treated milk except for $\mathrm{C}_{4}(P<0.05)$. Total concentrations of short-chain FFA were significantly increased in the 20- and 30-min treatments compared with those in raw milk and 10-min treatments. The present study indicated that pressurization for 30 min showed enhanced lipolysis.

\section{Free $A A$}

There was slight increase in most of individual and total AA between the raw milk and HPLT-treated milk (Table 3). The total free AA amount increased steadily with treatment time. The amounts were 110.65 and $131.93 \mu \mathrm{mol} / \mathrm{L}$ in the raw and 30-min-treated milk, respectively. Even though some of the individual AA concentrations were increased with the 30-min treatment in the present study, we were unable to explain this.

\section{Water-Soluble Vitamins}

The concentrations of L-ascorbic, niacin, and riboflavin were significantly lower in the HPLT-treated milk than in the raw milk regardless of treatment time ( $P$ 
Table 4. Water-soluble vitamin concentration of high pressure-low temperature treated milk at $200 \mathrm{MPa}$ and $-4^{\circ} \mathrm{C}$

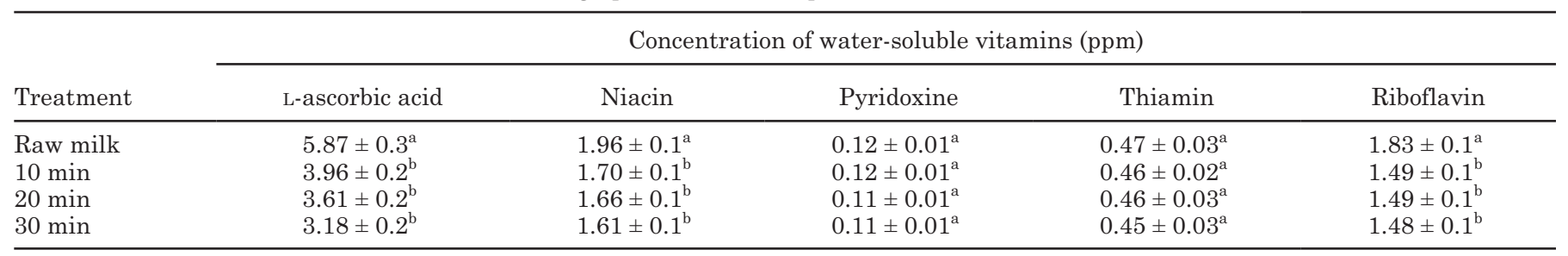

${ }_{\mathrm{a}, \mathrm{b}}$ Means within a column with the same superscript are not significantly different $(P>0.05)$.

$<0.05)$. A significant decrease was found in L-ascorbic acid and riboflavin concentrations by HPLT treatment. However, no difference was found in pyridoxine and thiamine concentrations in milks (Table 4).

The nutritive value of dairy products is based on that of milk itself and is affected by the processing technology used. Even though some of the water-soluble vitamins were destroyed by pressurization, few changes in the water-soluble milk components were shown. Lipinski (2003) noted that pasteurized milk could have up to a $66 \%$ loss of vitamins A, D, and E. Vitamin C loss usually exceeds $50 \%$. Heat affects water-soluble vitamins and could make them 38 to $80 \%$ less effective. Another study (Heppell, 2002) pointed out that riboflavin and niacin are generally not affected by heat treatment. Pasteurization does involve a minor loss (10\%) of thiamin and vitamin $B_{12}$ content, as well as a $20 \%$ loss of vitamin C content. Bendicho et al. (2002) investigated the effects of high-intensity pulsed electric field treatments at room or moderate temperature on water-soluble vitamins (thiamine, riboflavin, and ascorbic acid) and compared the results with conventional thermal treatments. They observed no or little changes in vitamin content after high-intensity pulsed electric field or thermal treatments except for ascorbic acid. Milk retained ascorbic acid after low $\left(63^{\circ} \mathrm{C}, 30 \mathrm{~min} ; 49.7 \%\right.$ retained) or high $\left(75^{\circ} \mathrm{C}, 15 \mathrm{~s} ; 86.7 \%\right.$ retained) temperature pasteurization treatments. Therefore, it can be postulated that HPLT treatment could have potential as a milk processing technology.

\section{Color}

Table 5 compared the color value between the untreated raw milk and HPLT-treated milk. The L-values of treated milks decreased with treatment time, whereas a-values were increased. In the case of a-values, the 10-min treatment did not show significantly different values from the raw milk. The a-values were slightly but significantly increased after the 20-min HPLT treatment. The b-values showed the same general trend as the a-values. The L-value in all HPLT-treated milks was significantly lower than that of the raw milk $(P<0.05)$. However, there was no difference in L-values among the treated milks. The lowest L-value was found (65.51) with the 30-min treatment. Huppertz et al. (2002) reported that HP treatment reduced the Lvalue of milk, presumably due to disruption of casein micelles. The total change $(\Delta \mathrm{E})$ with HPLT is shown in Figure 4 . The difference of color, which was presented as $\Delta \mathrm{E}$, was greatest for the 30-min treatment compared with the 10- and 20-min treatments. Based on above results, color change occurred with the longest HPLT treatment.

Gervilla et al. (2001) indicated that pressure was the main factor on total color difference and some authors reported similar results in the behavior of milk color under HP treatments (Adapa et al., 1997). On the other hand, the decrease in L-value could have been mainly due to disintegration of casein micelles by pressure into small fragments that increase the translucence of the milk.

\section{Viscosity}

Table 5 indicates changes in the viscosity of HPLTtreated milk. The viscosity value for the raw milk was $0.75 \mathrm{cps}$ and those of treated milks for 10,20 , and 30 min were $0.75,0.75$, and 0.79 , respectively, which were not significantly different from that of raw milk

Table 5. Changes in color (L-, a-, b-values) and viscosity of high pressure-low temperature treated milk at $200 \mathrm{MPa}$ and $-4^{\circ} \mathrm{C}$

\begin{tabular}{lcccc}
\hline Treatment & L-value & a-value & b-value & Viscosity (cps) \\
\hline Raw milk & $75.72 \pm 2.1^{\mathrm{a}}$ & $-3.19 \pm 0.1^{\mathrm{a}}$ & $3.58 \pm 0.1^{\mathrm{c}}$ & $0.75 \pm 0.05^{\mathrm{a}}$ \\
10 min & $70.61 \pm 2.5^{\mathrm{b}}$ & $-3.21 \pm 0.1^{\mathrm{a}}$ & $4.48 \pm 0.1^{\mathrm{a}}$ & $0.75 \pm 0.02^{\mathrm{a}}$ \\
20 min & $69.87 \pm 1.9^{\mathrm{b}}$ & $-2.92 \pm 0.1^{\mathrm{b}}$ & $3.62 \pm 0.1^{\mathrm{c}}$ & $0.75 \pm 0.03^{\mathrm{a}}$ \\
30 min & $65.51 \pm 2.0^{\mathrm{c}}$ & $-2.95 \pm 0.1^{\mathrm{b}}$ & $3.96 \pm 0.1^{\mathrm{b}}$ & $0.79 \pm 0.01^{\mathrm{b}}$ \\
\hline
\end{tabular}

${ }^{\mathrm{a}-\mathrm{c}}$ Means within a column with the same superscript are not significantly different $(P>0.05)$. 


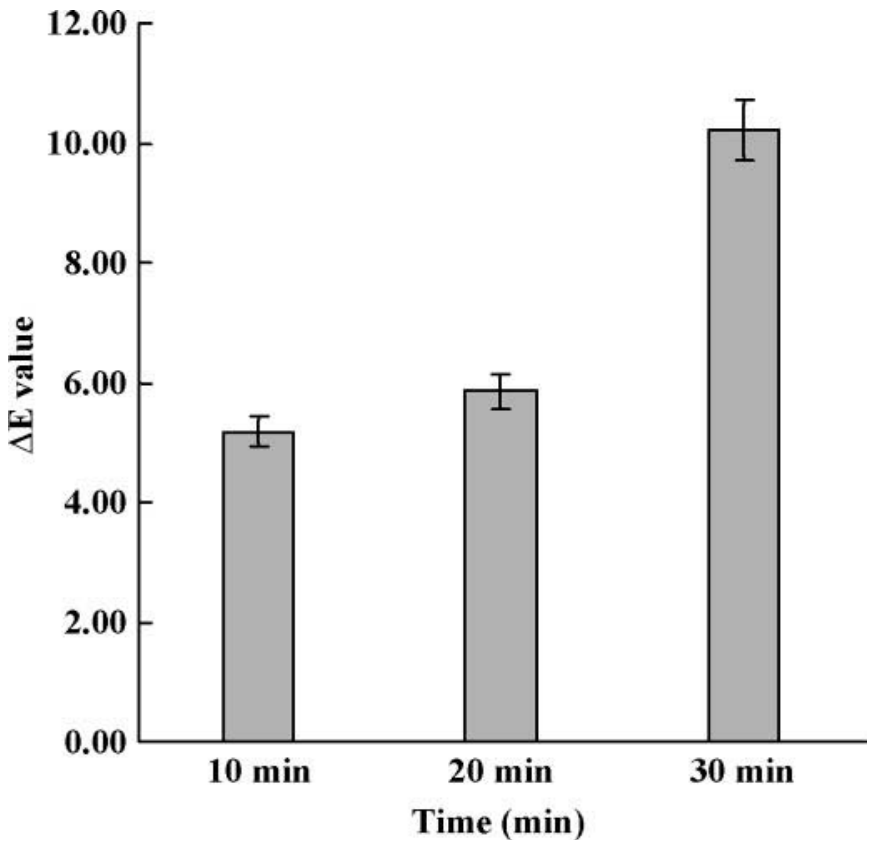

Figure 4. Changes in color difference of high pressure-low temperature treated milk at $200 \mathrm{MPa}$ and $-4^{\circ} \mathrm{C} . \Delta \mathrm{E}=$ the total color difference between raw milk and treated sample: $\Delta \mathrm{E}=\left[(\Delta \mathrm{L})^{2}+(\Delta \mathrm{a})^{2}\right.$ $\left.+(\Delta \mathrm{b})^{2}\right]^{1 / 2}$.

$(P>0.05)$. This result suggested that even the $30-\mathrm{min}$ HPLT treatment did not result in any change in viscosity in milk.

\section{CONCLUSIONS}

The effect of HPLT on physicochemical properties in milk was investigated. With a treatment of $200 \mathrm{MPa}$ pressure at $-4^{\circ} \mathrm{C}$, protease and lipase activities were highly inactivated regardless of treatment time. Among nutrients, L-ascorbic acid, niacin, and riboflavin were significantly lower with the HPLT treatment compared with raw milk. Among other physicochemical properties, the L-value was significantly lower in the HPLTtreated milk than in the raw milk. The present study showed the first evidence of the potential for applying HPLT treatment in milk; further study will be necessary.

\section{ACKNOWLEDGMENTS}

This study was supported by a grant of the Brain Korea 21 Project in Seoul, Republic of Korea.

\section{REFERENCES}

Adapa, S., K. A. Schmidt, and R. Toledo. 1997. Functional properties of skim milk processed with continuous high pressure throttling. J. Dairy Sci. 80:1941-1948.
Bendicho, S., A. Espachs, J. Arantegui, and O. Martino. 2002. Effect of high intensity pulsed electric fields and heat treatments on vitamins of milk. J. Dairy Res. 69:113-123.

Buchheim, W., K. Schrader, C. V. Morr, E. Frede, and M. Schutt. 1996. Effects of high pressure on the protein, lipid and mineral phase of milk. Int. Dairy Fed. 2:202-213.

Chae, S. K. 2002. Pages 675-681 in Standard Food Analysis. Theory and Practice. Ji-Gu Publishing Co., Seoul, Korea.

Gervilla, R., V. Ferragut, and B. Guamis. 2001. High hydrostatic pressure effects on color and milk-fat globule of ewe's milk. J. Food Sci. 66:880-885.

Hegenauer, J., P. Saltman, D. Ludwig, L. Ripley, and P. Bajo. 1979. Effects of supplemental iron and copper on lipid oxidation in milk. 1. Comparison of metal complexes in emulsified and homogenized milk. J. Agric. Food Chem. 27:860-867.

Heppell, N. J. 2002. Continuous-flow heat processing. Chapter 22 in Nutrition Handbook for Food Processors. C. J. K. Henry and C. Chapman, ed. CRC Press, Washington, DC.

Hite, B. H. 1899. The effect of pressure in the preservation of milk. West Virginia Agric. Exp. Stn. Bull. no. 58:15-35.

Hodgin, J. C., P. Y. Howard, and D. M. Ball. 1983. An automated device for in situ pre-column derivatization and injection of amino acids for HPLC analysis. J. Chromatogr. Sci. 221:503-507.

Hong, G. P., S. H. Park, J. Y. Kim, and S. G. Min. 2006. The effects of high pressure and various binders on the physico-chemical properties of restructured pork meat. Asian-australas. J. Anim. Sci. 19:1484-1489.

Huppertz, T., A. L. Kelly, and P. F. Fox. 2002. Effects of high pressure on constituents and properties of milk. Int. Dairy J. 12:561-572.

Ikins, W. G., H. S. Kwak, G. S. Zink, and I. J. Jeon. 1988. Comparison of methods for quantitation of free fatty acids in cheese. J. Food Sci. 53:1915-1916.

Knorr, D. 1993. Effects of high hydrostatic pressure processes on food safety and quality. Food Technol. 47:156-161.

Kolakowski, P., A. Reps, and A. Fetliński. 2000. Microbial quality and some physico-chemical properties of high pressure-processed cow milk. Polish J. Food Nutr. Sci. 9:19-26.

Lindroth, P., and K. Mopper. 1979. High performance liquid chromatographic determination of subpicomole amounts of amino acids by precolumn fluorescences derivatization with o-phthaldialdehyde. Anal. Chem. 52:1667-1674.

Lipinski, L. 2003. Wise Traditions in Food, Farming and the Healing Arts. The Weston A. Price Foundation, Washington, DC.

López-Fandiño, R. 2006. High pressure-induced changes in milk proteins and possible applications in dairy technology. Int. Dairy J. 16:1119-1131.

Luscher, C., J. K. Sunderhoff, and D. Knorr. 2005. Pasteurisation of meat in frozen conditions by high pressure. Proceedings of Innovations in Traditional Foods, Valencia, Spain. Intrafood $2: 1379-1382$

Sancho, F., Y. Lambert, G. Demazeau, A. Largeteau, J.-M. Bouvier, and J.-F. Narbonne. 1999. Effect of ultra-high hydrostatic pressure on hydrosoluble vitamins. J. Food Eng. 39:247-253.

SAS Institute. 1985. Users Guide: Statistics, Version 5 ed. SAS Institute Inc., Cary, NC.

Trujillo, A. J., M. Capellas, J. Saldo, R. Gervillan, and B. Guamis. 2002. Applications of high-hydrostatic pressure on milk and dairy products: A review. Innov. Food Sci. Emerging Technol. 3:295-307.

Urrutia Benet, G., O. Schlüter, and D. Knorr. 2004. High pressure-low temperature processing. Suggested definitions and terminology. Innov. Food Sci. Emerging Technol. 5:413-427.

Wagner, W., A. B. Saul, and A. Pruß. 1994. International equations for the pressure along the melting and along the sublimation curve of ordinary water substance. J. Phys. Chem. Ref. Data 23:515-527. 